\title{
Sob o signo do consumo: status, necessidades e estilos
}

Introdução

"Era uma vez um homem que vivia na Raridade. Depoisdemuitas aventurase de longa viagem através da Ciência Econômica, encontrou a Sociedade da A bundância. Casaram-se e tiveram muitas necessidades."1

MuITAS VEZES, procura-sejustificar as práticas consumistas em torno da descoberta das necessidades das pessoas e da procura de objetosparasatisfazêlas. Estavisão pressupõe queasnecessidadeshumanassãotão objetivas que é possível identificar suas causas e suas respectivas soluções. Não que isso seja impossível, masestemovimento não acontece deforma tão simples assim. Desconsidera-se aí todaaabstraçãoqueenvolveossentimentos, gostos e estímulos que embasam o sistema das necessidades e satisfações das pessoas.

O consumo encontra-se no campo da complexidadehumana-envolveseusvalores, desejos, hábitos, gostos e necessidades. Daí importa perguntar: o que dá sentido ao consumo? Em que termos as pessoas o definem? $O$ que as estimula a praticá-lo continuamente?

As linhas que seguem procuram mergulhar, ao menos na superfície, do universo de três autores que buscam compreender a "sociedade de consumo" atual. Jean Baudrillard, Gilles Lipovetsky e Mike Featherstone abordam vários e diferentes aspectos deste tema na tentativa deoferecer uma explicação sobreo consumo- oqueesteofereceàspessoas

Mariângela Machado Toaldo Mestranda em Comunicação Social FAMECOS/ PUCRS eo queestas buscam nele. Partiremos daobra de Jean Baudrillard - Para uma crítica da economia política do signo - onde o autor defende que, para além do valor de troca eo 
valor de uso dos objetos, o que prepondera é seu valor-signo, sua capacidadederepresentar. Em contraponto a Baudrillard, Gilles Lipovetsky, em 0 império do efêmero, investe na superioridade das necessidades das pessoas. Diantedamultiplicidadedeescolhas, hoje existentes, acredita na autonomia dos sujeitosperanteseusgostosenecessidades. Já Mike Featherstone fala sobre a importância dos estilos de vida para os indivíduos. Entre outrospontos, são al gumasobservações sobre os gostos e estímulos dos sujeitos que provocam seu movimento entre os estilos de vida que ele registra no livro Cultura de consumo e pós-modernismo.

Essas idéias fazem parte de um recorte específico quepossibilitacompreender avisão dos autores, de uma forma geral, sobre a cultura e os objetos de consumo. Seus pensamentos não selimitam aos pontos aqui ressaltados, oferecem, contudo, recursos para desenvolver a abordagem em questão e estimular a continuidade de seu estudo.

\section{Baudrillard e o Objeto-Signo}

Para uma crítica da economia política do signo foi publicado em 1972, em Paris. N estelivro, Jean Baudrillard faz uma abordagem crítica daeconomiadeconsumo, descaracterizandoa como "sociedadedeconsumo" eaproximando-a da ideologia. Sua teoria se desenvolve a partir da concepção sígnica dos objetos de consumo, os quais denomina objetos-signo.

Osobjetos deconsumo, para Baudrillard, são lugares de trabalhos simbólicos, onde se procura constituir uma moral do consumo, baseada em valores "sociais", como o ter, a ostentação e a distinção. Eles se renovam, sustentados pelos mesmos valores. A necessidade deacompanhar suas mudanças, cada vez mais efêmeras, é passada aos indivíduos como meio para alcançar sua realização. $\mathrm{Na}$ verdade, esta é apenas substituída por outros objetos, por outras ilusões. Segundooautor, "amodamovimenta- sena seguintelógica: necessidadedeinovar e nada mudar na ordem fundamental". ${ }^{2} \mathrm{Ou}$ seja, a satisfação das necessidades continua insatisfeita.

O objeto-signo, segundo Baudrillard, é um instrumento para manter e concretizar relações de consumo e de diferenciação social advenientes. Não éo simbolismo desteobjetosigno nem sua utilidade que lhe dão sentido. O estímulo para sua aquisição se dá a partir deumconjuntodeconotaçõesepropriedades que lhe diferencia de outros objetos, conferindo osmesmos atributosa seu usuário. Não seconsome o objeto em si, pela sua utilidade, e sim pelo que ele representa, pela sua capacidade de diferenciar, de remeter o consumidor a uma determinada posição, a um determinado status. Daí a característica sígnicado objeto, queengloba oval or detroca e o valor de uso do mesmo, sendo preponderanteaeles. Assim, vigoraumaclassificação dosindivíduosatreladaàconstanterenovação do material distintivo (objeto de consumo) e seu respectivo uso.

A significação social de um objeto (seus valores, qualidades, vantagens...) tem sua forçanatroca, nasposições queosindivíduos sãoestimuladosaocupar - sempreem relação a seus semelhantes. Baudrillard diz que "o sentido nunca tem origem na relação (...) econômica, (...) racionalizada em termos de escol ha edecálculo entreum sujeito (...) eum objeto (...), masnumadiferençasistematizável em termos de código (....)."3

Os indicadores das "novas" tendências mudam constantemente de objetos, assim como retornam ao que, anteriormente, foi considerado ul trapassado. Não há coerência e sim contradição. "O valor de moda é reversível", ${ }^{4}$ os efeitos debeleza, o sentimento de utilidade e distinção estão nos mais diversos objetos, basta acreditar neles.

ParaBaudrillard, alógicadoconsumo provoca algumas ilusões, a começar pela idéia de satisfação "real" dos indivíduos. Os meios 
"realizadores" das pessoas, sugeridos pelo consumo, nunca encontram lugar fixo, estão sempreem "coisas" diferentes einferiores às expectativas geradas. Assim, é possível que eles dêem conta de satisfações mais superficiais e não de aspectos profundos da vida humana, como muitas vezes propõem. A buscadadistinçãosocial, através do consumo, é outro engano, segundo o autor. A diferença entreas pessoas, os grupos, não semanifesta apenas naquilo que exteriorizam. Há todo um conjunto de concepções, hábitos, gostos, comportamentos, conhecimentos, compondo os sujeitos. Os limites da aparência não conseguem comunicar sua essência, por isso, não servem de parâmetro para classificar os sujeitos como iguais ou não. Acreditar que vivemos numa "democracia do consumo" ${ }^{5}$ é mais uma ilusão para Baudrillard. Como na observação anterior, não podemos compreender a semel hança das pessoas pelo queelas consomem. Há diferença de escolhas, de gostos, devalores, depossibilidadesque, antes dedemocratizar a sociedade, colaboram com a manutenção de determinadas posições.

O termo "sociedade de consumo" para ele tambéméuma construção enganosa. Seu uso corrente supõe que o consumo seja um valor universal para a satisfação das necessidades das pessoas. $\mathrm{Na}$ verdade, diz Baudrillard, "trata-se de uma instituição e de uma moral (...) e deum elemento da estratégia do poder. A sociedade é aqui, a maior parte das vezes, ingênua e cúmplice: toma a ideologia do consumo pelo próprio consumo". ${ }^{6} \mathrm{~A}$ adesão dos sujeitos às práticas consumistas, à ânsia pelo “novo", pelaposseepeladistinção, acaba conferindo uma estratificação social dos mesmos sob a promessa do seu oposto. Os objetos significam também o limite das possi bilidades das pessoase, assim, marcam seus lugares no social.

\section{Lipovetsky e a Satisfação das Neces- sidades}

Gilles Lipovetsky situa-se na esteira dos movimentos deidéiasqueefervesceramapós 68. 0 império do efêmero, publicado em 1987, na França, gerou muita discussão em torno do tema abordado, principalmente pelo fato deo autor anal isar o consumo sob um prisma mais positivo que negativo. Segundo ele, as práticas consumistas podem colaborar na educação deváriosaspectos da vidahumana.

Para Lipovetsky, o surgimento de uma multiplicidade de oferta possibilitou uma multiplicidade de escolha. As pessoas são estimuladas a pesquisar seus gostos, costumes, personalidadeeinvestir emsi apartir de suas próprias características e não segundo a dos outros. Hoje, os indivíduos buscam legitimar-se e não legitimar o grupo ao qual pertencem. Assim, o autor contesta a idéia de que os processos de diferenciação social comandem o consumo de massa.

Gilles Lipovetsky caracteriza a época do consumo atual como um momento em quese busca "prazer para si mesmo". Segundo ele, as necessidades humanas estão no valor de uso - o que Baudrillard diz ser apenas um suporte -, na utilidade aliada à imagem. $O$ gozo íntimo, as qualidades do objeto, a sensação, o espetáculo, o culto ao corpo, o novo, a autonomia, a informação... preponderam sobrea preocupação com o outro. ${ }^{7}$ A té os produtos de grife não significam apenas diferenciais sociais, testemunham a "tendência neonarcísica de se dar prazer, de um apetite crescente de qualidade e de estética (...), o prazer da excelência técnica, da qualidade e do conforto absolutos". 8

O valor de uso liga o homem às coisas que, por sua vez, na sociedade de consumo, mudam constantemente. A hiperescolha, a sedução e a inconstância embasam os processos da moda e predispõem o homem constantemente ao desprendimento do que foi adquirido. As coisas são dessubstancializadas pela moda através da utilidade e da novidade. ${ }^{9}$ Este movimento significa, para Lipovetsky, uma democratização do mundo material. Aocontrário deBaudrillard, 
ele acredita que o consumo estimula essa democratização pelo fato de oferecer uma variedade cada vez maior de objetos que se tornam instrumentos de escolha dos indivíduos. Segundoseu raciocínio, osindivíduos têmigual liberdadeepossibilidadeparaoptar entre um objeto e outro, apegando-se ou não a eles conforme sua própria vontade.

A moda, então, instigou o indivíduo a autodeterminar-se, a ser mais "sujeito da sua existênciaprivada, operador livredesuavida por intermédio da superescolha na qual estamos imersos"10 para conquistar sua realização pessoal. Lipovetsky vêna idéia de autonomia do sujeito a não continuação da distância social pela "universalização dos padrões modernos" ${ }^{11}$ oferecidos a todos.

Com sua ênfase nas necessidades e escol has individuais, aponta a falha de Baudrillard, entreoutros, em não ter considerado o "vetor de indeterminação na cultura da moda"12 sempre presente através das características e particularidades de cada um. Pela própria influência da moda os sujeitos tornaram-se volúveis, "sem apego profundo, móvel, de personal idade edegostos flutuantes"13 - um empecilho, portanto, para as classificações sociaisdeterministas. Lipovetsky sal ientaque édisso mesmo quea lógica da moda precisa: sujeitos maleáveis como ela. Mas o autor compreende que esse aspecto col abora para socializar os seres na mudança, preparandoos para a reciclagem permanente. ${ }^{14} \mathrm{~A}$ familiaridade com essa predisposição contribui "para acelerar as mutações em curso, constituir uma sociedade armada em face das exigências continuamente variáveis do futuro"..$^{15}$

Gilles Lipovetsky observa, ainda, que, teoricamente, a modaimpulsionaà inovação, mas o imobilismo dos interesses pessoais e das vantagens adquiridas podesemanifestar na prática. A ênfase no "para si", o estímulo emsatisfazer asprópriasnecessidades podem ofuscar o olhar para a preocupação com o social. Neste sentido, os prejuízos, os problemas dos outros e da sociedade como um todo, em seus diversos aspectos, não são limites para a realização dos interesses particulares. $O$ autor admite, a partir de suas concepções sobre a dinâmica da moda, que ela contribui com o privilégio do eu sobre o todo, prejudicandoocomprometimentosocial dos indivíduos. A administração desse impasse, no entanto, el ereserva às instâncias políticas.

\section{Featherstone e o Estilo de Vida}

Em Cultura do consumo e pós-modernismo, Mike Featherstone desenvolve uma abordagem do consumo de acordo com o contexto desta época chamada pós-moderna. A pesar de partilhar da maioria das idéias de Baudrillard, ele imprime uma mudança de rumo na discussão sobre o consumo ao acrescentar o conceito de estilo de vida.

Estilo de vida, segundo Featherstone, na cultura de consumo contemporânea conota individualidade, auto-expressão e uma consciência de si estilizada. ${ }^{16}$ Assim, o indivíduo expressa-se através da roupa, do carro, dasopções quefaz edo comportamento que adota. A multiplicidade de escol has favorece o rompimento de fronteiras préestabelecidas entre os estilos de vida. Estes não requisitam mais prioridade a seus adeptos. Esta característica atual interfere na solidez dosgruposdereferências, permitindo a mescla de costumes, o descompromisso com seus princípios e, conseqüentemente, a desestabilização da sua autonomia. Isto, porém, não significa o fim das distinções sociais, mas um novo movimento no interior do social.

Os próprios avanços tecnológicos oferecem uma maior variedade de escolha, o que não significa um princípio de igual dade, embora essa promessaexista. Para Featherstone, mais capacidade técnica significa mais variedade de produtos e, em conseqüência, uma maior diferenciação a ser incorporada nas séries de 
produção. Os produtos podem se oferecer parecidos e as ofertas compensatórias, equivalentes, masaessênciarevelaadiferença. É omercadoquesefragmenta. Osindivíduos, por sua vez, consomem cada vez mais produtos diferentes.

Featherstone se vale de Bourdieu para salientar que os elementos, em cada campo social específico, possuemvalores diferentes, os quais determinam a preferência de cada grupo por determinados bensculturais. Estes são, ao mesmo tempo, "marcadores de classe", ${ }^{17}$ indicadores de posição social e, assim, refletem o "poder" desta classe em detrimento de outras. A reprodução das relações entre si e os outros é a garantia de manutenção da sua legitimidade e singularidade. $\mathrm{O}$ acesso aos diferentes campos se pretende limitado, pois o valor dos seus valores está na distinção e não na sua popularização. O quepassaa ser do acesso de todos, ou deumgrandenúmero,jánão destaca ninguém. O objetivo de preservar a singularidade é justamente garantir o "privilégio" daqueles que acreditam diferenciar-se por meio de certos elementos.

A escol hadosvaloresquesetransformamem bensculturaisnão sedánecessariamentepelo fator econômico. Cadasistemadevalorestem sua própria lógica, gostos e características. Featherstone diz que as pessoas, hoje, constroem seu estilo de vida, onde manifestam sua individualidade, através do que se apropriam. Elas têm consciência de que se comunicam por meio do estilo adotado, que serão "interpretadaseclassificadasemtermos da presença ou falta de gosto". ${ }^{18}$

Aspessoasmaisjovens, jáadaptadasàcultura de consumo atual, possuem um sentimento de curiosidade, de gosto pelo novo, são predispostas a experimentar o diferente em nome de suas expectativas. $\mathrm{N}$ ão abandonam a segurança da legitimidade de seu estilo, mas redimensionam-no em busca de novas sensações, de práticas "sempre mais estimulantes", de afinidades que vão surgindo com o processo social. Não há mais uma preocupação rígida em garantir um único estilo de vida, mas um estilo. Não importa se sua composição se dá a partir de diferentes tendências.

Featherstoneidentificaalguns "instrumentos" colaboradores desse movimento mais solto que se verifica entre as novas tendências. Além da lógica do consumo, estimuladora constante da renovação de estilos de vida, o autor ressalta a presença de intermediários culturais, cada vez mais diferentes - quevão desde grupos de intelectuais até a mídia e seus desdobramentos. Aqui, incluem-se pessoas, instituiçõeseórgãosenvolvidoscom a circulação permanente dos bens culturais. Estes passam a ser analisados, registrados, preservados, legitimados ou ignorados de acordo com os interesses e objetivos de sua divulgação. Aliada ao tratamento dado aos produtos culturais está a articulação, a representaçãoeatransmissão deexperiências, costumes evalores sociais. Aí se manifesta a dimensão social dos estilos de vida, possível uma vez que o homem vive em sociedade, mas reforçada pela construção que se real iza a partir dos bens culturais.

O processo deglobalização, paraFeatherstone, vem colaborar com o desenvolvimento desta dimensão social dos estilos, já que possibilita o aumento da circulação das informações, envolvendo as mais diversas culturas. As hierarquiastradicionaisperdemahegemonia, cedendolugar às diferentes vozeseestímulos dos intermediários culturais. O mesmo acontece com seus produtos. Estes não conservam mais a "aura" tão valorizada no passado, mas passam por constantes adaptações e caracterizações. Os instrumentos que ajudam a interpretar os estilos existentes eas "novas" tendências se multiplicam, estimulando um movimento que "leva em conta as novas circunstâncias de produção dos bens culturais". ${ }^{19}$ As tendências, os estilos se consagram nos objetos deconsumo, cada vez maisvariados, rompendoashierarquias, mas conservando as diferenças. 
Em busca da síntese...

O breveolhar sobreasteoriasabordadasantes de proporcionar o acordo de idéias em torno de uma síntese, ressaltam aspectos e problematizações envolvidos na questão do consumo. É acontinuidadedareflexão destes pontos que pode conduzir a um maior esclarecimento a seu respeito, ou à indicação de brechas que precisem ser mel hor exploradas para uma compreensão mais profunda da "cultura de consumo".

Featherstonedizqueosindivíduosconstituem seu estilo de vida baseando-se nas suas características "pessoais", nas quais agregam o gosto pelo novo. Observa, no entanto, quea disposição a aderir às novidades tem um pouco deaventura, ousadia, mas também de segurança. Talvez, a partir desta dicotomia possamos entender, pelo menos, um pouco da complexidade que é decodificar o significado e o uso de bens culturais.

É preciso compreender, em primeiro lugar, queas decisõesdeconsumo, osatosdecompra não ocorrem a partir de motivos isolados. $A$ sugestão de Baudrillard, do objeto-signo, ea deLipovetsky da satisfação das necessidades das pessoas, não são excludentesnem mesmo por estesautores-emboracadaumapostena preponderância dasua hipótese. O consumo, sendo justificado tanto pelo valor distintivo do objeto, como pelo estilo de vida dos indivíduos ou pelas necessidades destes, envolve inúmeras dimensões sociológicas, psicológicas, como também os fatores racionais e financeiros.

Satisfação das necessidades, possibilidades de escolha, gostos, são conceitos tão amplos, capazes deenglobar inúmerosdeterminantes, inclusive a diferenciação social. O homem busca oqueparaelepareceser útil, masquem o seduz primeiro: a utilidade em si ou a imagem construída a partir de atributos (o objeto-signo emação)? Difícil discernir.Todos osmotivosquelevamao consumo, a aderir às tendências da moda, mexem com o prazer, com as motivações íntimas e existenciais. 0 homem também encontra prazer próprio na diferença, como, por exemplo, nas marcas de grife. A intenção, neste caso, pode ser de um consumo dequal idade parasi, como acredita Lipovetsky. O diferencial do consumo em relação ao outro, o privilégio da possibilidade douso deumadeterminadamarca, noentanto, acaba seexteriorizando esignificando. Assim o "para si mesmo" acaba sendo um prazerosamente "para o outro".

É preciso concordar com Baudrillard e Featherstone quando salientam a conscientização das pessoas em relação à capacidade sígnica dos estilos adotados. Não sendo possível, assim, classificar osobjetivosestritos de cada compra. Antes, podemos nos contentar em compreender que o consumo tem em sua base um significado ambíguo, difuso, definido por múltiplos motivos, conscientes e inconscientes.

As idéias de "democratização do mundo material", "liberdade de escolha" e "autonomia do sujeito" também estão implícitas nas práticas de consumo. Contudo, é preciso refletir um pouco sobre estes conceitos. $\mathrm{O}$ pressuposto da "democratização do mundo material", sugerido por Lipovetsky, é a igualdade e a liberdade da escolha dos "padrões modernos" oferecidos a todos.

Fazemos parte, então, de uma democracia que nos permite escolher e trocar objetos, adotar ou excluir tendências, mas queoferece apenas o contexto do consumo como opção para o seu exercício. É aí que se pretendeum indivíduo livre, autônomo, convidado ininterruptamentea escolher, aderir, mudar, consumir, assumir modelos dentro da lógica descartável, que sustenta o consumo.

A existência das múltiplas ofertas, por sua vez, nãogaranteapossibilidadedasmúltiplas escolhas. Há a possibilidade de circulação entre as diferentes tendências, faltam, no entanto, as condições para que isso se concretize de fato. Esse movimento envolve 
umasériededimensõesqueabrangedesdeas características aparentes - como a estética até as características "pessoais" dos indivíduos e o fator econômico dos mesmos. Estes elementos não podem ser desconsiderados, nem as infusões psicológicas e sociológicas que constantemente incidem sobre eles.

O fato dastendências do consumonão estarem mais restritas às vitrines das lojas, mas expostas nas pessoas, nos lugares, nos carros, namídia, favorecemaisainfluência dosgostos que a individualidade de suas escolhas. Featherstone observa que o prazer da utilização das diferentes tendências se dá quando elas são legitimadas. Daí o engajamento das pessoas a determinados estiloseo direcionamento de sua "liberdade", pois, do contrário, elas podem não significar o que pretendem.

A liberdade total das opções não vigora de fato. A prática daquilo que se propõe acaba requerendolimitesnosocial. O ol har dooutro, as mensagens que embasam um estilo, os estereótipos já formulados em torno de determinados bens e comportamentos tornam-se, mesmo que inconscientemente, condicionantes do consumo, limitadores das opções.

Por outro lado, a multiplicidade de ofertas não garante a multiplicidade de escolhas, porque os sujeitos não são iguais. Os objetos de consumo realmente se oferecem a todos, masatodosquetenham condiçõesfinanceiras para adquiri-los, a todos que compartilhem os mesmos gostos e val ores neles representados. As diferenças manifestas nos gostos, costumes, conhecimentos, atitudes econcepções dossujeitos precisamencontrar al gumas afinidades naquilo que lhes é oferecido. $A$ "bagagem" individual queos sujeitos trazem consigo elabora-se e reelabora-se constantemente com a colaboração de diferentes fontes, entreelas, os intermediários culturais. O misto de opiniões, sugestões, indicadores deprocedimentosqueosindivíduos recebem não os impedem de fazer suas próprias sínteses. Ao contrário, eles os adaptam de acordo com os estímulos recebidos, suas expectativas e o conjunto de características que possuem. O resultado dessa articulação acaba restringindo o âmbito de opções dos sujeitos, através daseleção degostos, práticas e estilos.

As múltiplas ofertas revelam, então, sujeitos diferentes e escolhas diferentes, não abundantes, talvez, nem variadas. Bourdieu e Williams ${ }^{20}$ observam que a idéia dos indivíduos possuírem os mesmos bens antes de indicar a igualdade dos mesmos, reflete o limite desuas possibilidades. Limiteesteque se apresenta, especialmente, na dificuldade da realização de escolhas sem influências externas e sem a consideração do poder aquisitivo dos sujeitos.

Neste sentido, Baudrillard e Featherstone salientamqueaspráticas doconsumoacabam refletindo o "poder" de al guns grupos pelos privilégiosquelhessão reservadosemtermos de possibilidade de aquisição. Este fator não se manifesta no acúmulo de objetos de consumo, mas na vantagem de possuir bens dealtaqualidade, queosdistinguedosdemais. Assim, a classificação diferenciada dos indivíduos no social acaba aparecendo. Os aspectos externos, como os bens deconsumo, por exemplo, podemser seu primeiro indício. A aparência, no entanto, revela-seinsuficiente para definir os sujeitos sem considerar a complexidade de seus modos de vida e concepções. ${ }^{21}$

Independentedosequívocosdeconcepçõese crenças que a própria lógica do consumo possa promover, éa sua condição sígnica que não se pode desconsiderar. Ela embasa as práticas consumistas, recobrindo os objetos de atributos e abstrações sedutoras. São os signos daí emergentes que apelam ao imaginário dos sujeitos, fazendo-os conceber a possibilidade da realização de suas expectativas em determinados objetos.

É a construção feita a partir destes objetos - 
suas propriedades, vantagens evalores - que indica sua(s) utilidade(s). Aí já não são mais as necessidades pura e simples, conscientes, dos sujeitos que se manifestam, mas aqueles sentimentosqueassugestões compreendidas nos objetos insistem em mostrar que fal tam emsuasvidas. Osestímulos daí provenientes oferecem "materiais" constantes para a formação dos estilos dos indivíduos e dos grupos.

São ossi stemas designos, portanto, mantidos e estimulados pela lógica do consumo, que fazemohomemrelacionar-se comelaprópria através dos objetos e das concepções de necessidade e realização. "Necessidades e prazeres", comodisseBaudrillard, sãoapenas "efeitos de palavra" 22 que encobrem a arquitetura sígnica que estrutura as práticas consumistas(B, SC, 80).

A ressalva de Featherstone de queas pessoas também procuram um lugar "seguro", "legítimo" no social refere-se exatamente à significação que assumem através dos bens adquiridos. Elas optam entre este ou aquele objeto, entre esta ou aquela proposta, considerando a posição (etodosos meandros que esta pode envolver) em que serão "enquadradas" socialmente.

O consumo para si quecomunica algo para o outroéapenasum viésem quesemanifestam as diferenças que os signos do consumo imprimem na sociedade. A união deste aspecto aos pontos já citados eaos que ainda se puder identificar levam a aceitar o fator distintivo do consumo. O que, a partir disso, incitaacuriosidadesão osmecanismosatravés dos quais sas construções sígnicas conseguem articular osdesejos, asnecessidadesecarências dos sujeitos em relação a seus semel hantes e aos objetos de consumo. Saber como se desenvolvea lógica da diferenciação na vida dos sujeitos para mantêlos em constante movimento deescolhaentreosobjetos, mesmo queaspromessas desatisfação nelesinseridas Ihes traga freqüentes decepções.

\section{Notas}

1 BAUDRILLARD, Jean. A sociedade de consumo. Rio de Janeiro, Elfos, 1995, p. 68.

2 BAUDRILLARD, Jean. Para uma crítica da economia política do signo. Paris, Gallimard, 1972, p. 39-40.

3 Idem, p. 78.

4 Idem, p. 79.

5 Termo usado pelos demais autores abordados e desenvolvido por Baudrillard em Para uma crítica da economia política do signo, op. cit., p. 53.

6 Baudrillard tenta desmitificar o termo "sociedade de consumo". Ver BAUDRILLARD, J., op. cit., p. 55.

7 LIPOVETSKY, Gilles. 0 império do efêmero. São Paulo, Companhia das Letras, 1989, p. 173.

8 Idem, p. 174-175.

9 A partir destepensamento, Lipovetsky começaadesenvolver seu raciocínio para mostrar como a moda pode colaborar no desenvolvimento da vida humana. Ver LIPOVETSKY, G., op. cit., p. 175.

10 São pontos positivos como estes que Lipovetsky reconhece comofrutodosprocessosdemudançaconstanteestimulados pela moda. Ver LIPOVETSKY, G., op. cit., p. 175.

11 Termo utilizado por LIPOVETSKY, G., op. cit., p. 175.

12 Idem, p. 176.

13 Id. Ibid.

14 Conclusão a partir do pensamento que LIPOVETSKY desenvolve em Para uma crítica da economia política do signo, op. cit., p. 177.

15 Id. Ibid.

16 FEATHERSTONE, Mike. Cultura de consumo e pósmodernismo. São Paulo, Studio Nobel, 1995, p. 119.

17 Termo dePierreBourdieu citado por FEATHERSTONE, M., 
op. cit., p. 125.

18 FEATHERSTONE, M., op. cit., p. 123.

19 Idem, p. 132.

20 Featherstone desenvolve algumas idéias de Raymond Williams e Pierre Bourdieu para abordar as diferentes características que envolvem as pessoas de acordo com 0 campo social em que se encontram. A este respeito ver FEATHERSTONE, Mike, op. cit., p. 123-128.

21 Observação inspirada nas ressal vas de Williams e Bourdieu in FEATHERSTONE, M., op. cit., p. 124.

22 BAUDRILLARD, Jean. A sociedade de consumo, op. at., p. 80 .

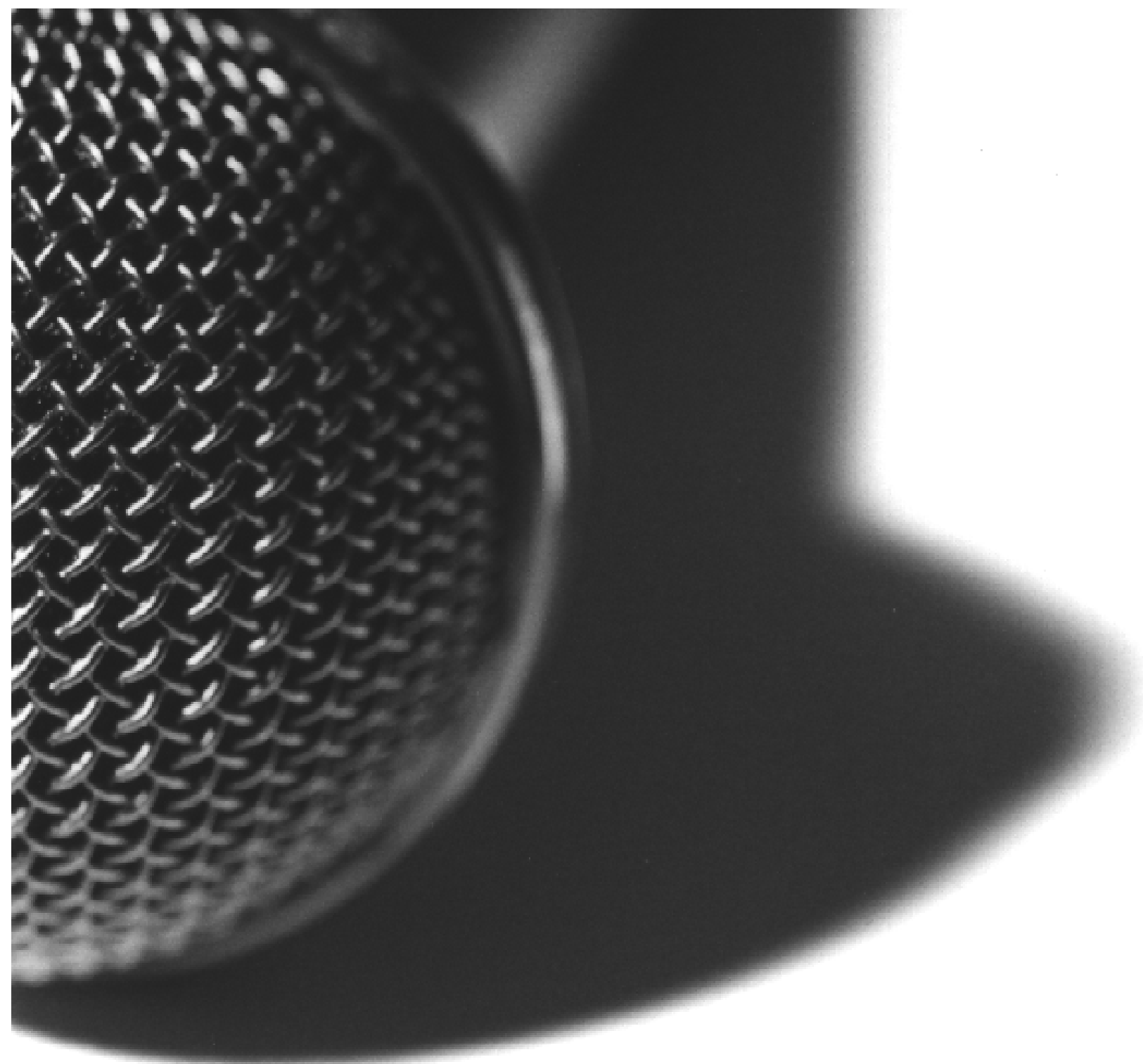

